\title{
ATUALIZAÇÃO DO IMUS CURITIBA
}

\author{
S. Pontes ${ }^{1}$; M. Rossi ${ }^{2}$; R. L. Witiuk ${ }^{3}$; F. B. von der Osten ${ }^{4}$ \\ 1,2,3 Graduando do curso de Engenharia Civil da Pontifícia Universidade Católica do Paraná \\ ${ }^{4}$ Professora do curso de Engenharia Civil da Pontifícia Universidade Católica do Paraná \\ samuel.pontes@pucpr.br', matheus.rossi@pucpr.br ${ }^{2}$,rafael.witiuk@pucpr.br ${ }^{3}$, fabiana.osten@pucpr.br ${ }^{4}$
}

Resumo: O crescimento acelerado e desordenado de grandes centros urbanos aliado à inércia das políticas de governo acarretaram diversos problemas urbanos, dentre estes, destacou-se a mobilidade urbana, temática do presente estudo. Nesse contexto, propóe-se atualizar o índice de mobilidade urbana sustentável (IMUS) para a cidade de Curitiba, com o intuito de confirmar a vocação deste índice como ferramenta de auxílio a tomada de decisão para o gestor de políticas públicas de transporte sustentável no contexto de uma mesma cidade.

Palavras-chave: IMUS, Curitiba, Mobilidade.

\section{Introduçáo}

Dentre as problemáticas urbanas presentes no cotidiano das cidades destaca-se a mobilidade, cujo conceito extrapola noção de transporte, envolvendo o direito de acesso à cidade pelos cidadãos e os impactos ambientais decorrente dos modais de transporte.

Na perspectiva de análise dessa temática $[1,2]$ se destaca o índice de mobilidade urbana sustentável (IMUS) como uma ferramenta de avaliação e monitoramento da mobilidade, assim como um referencial para a definição de políticas públicas visando a sustentabilidade dos sistemas de mobilidade urbana. $\mathrm{O}$ índice é composto por 87 indicadores que envolvem as três dimensôes da sustentabilidade: dimensão social, econômica e ambiental. Em 2010 esse indicador foi definido para a cidade de Curitiba [2], confirmando-a como benchmark nacional ao atingir nota de 0,747.

Tendo em vista as mudanças enfrentadas pela cidade de Curitiba nos últimos anos, principalmente no que tange ao aumento do uso do transporte individual, o presente artigo tem como objetivo atualizar o IMUS para a cidade, verificando a capacidade do indicador de representar as recentes mudanças. Além disso, objetiva-se atualizar o cálculo do índice a partir das novas fontes de dados propondo um terceiro elo de comparação para o IMUS da cidade.

\section{Metodologia}

O presente artigo visa reproduzir o cálculo do IMUS para a cidade de Curitiba realizando um estudo comparativo. Desse modo será realizada pesquisas em banco de dados governamentais, tratamento de dados em planilhas eletrônicas e utilização do software Arcgis para o tratamento de dados geográficos. Por fim os resultados serão comparados e sua evolução analisada. 


\section{Resultados esperados/Conclusóes}

Dado o agravamento da mobilidade em Curitiba é esperado um decrescimento do IMUS, o resultado dos 54 indicadores calculados até o momento aponta para a confirmação dessa tendência tendo em vista o resultado parcial de 0,732, cerca de 2,05\% menor que o obtido em 2010.

\section{Referências}

[1] COSTA, M. S. Um índice de mobilidade urbana sustentável. 2008. 274 f. Tese (Doutorado) - Curso de Doutorado, Programa de Pós-graduação em Engenharia Civil, Concentração Planejamento e Operação de Sistemas de Transportes, Universidade de São Paulo, São Carlos, 2008.

[2] MIRANDA, H. F. Mobilidade urbana sustentável e o caso de Curitiba. 2010. 178 f. Dissertação (Mestrado) Curso de Mestrado, Programa de Pós-graduação em Engenharia de Transportes, Escola de Engenharia de São Carlos, Universidade de São Paulo, São Carlos, 2010. 